\title{
Circulating IGF system and treatment outcome in epithelial ovarian cancer
}

\author{
Yu-Fang Huang', Wen-Fang Cheng ${ }^{2}$, Yu-Peng Wu', Ya-Min Cheng', Keng-Fu Hsu' \\ and Cheng-Yang Chou ${ }^{1,3}$
}

${ }^{1}$ Department of Obstetrics and Gynecology, National Cheng Kung University Hospital, College of Medicine, National Cheng Kung University, Tainan 70403, Taiwan

${ }^{2}$ Department of Obstetrics and Gynecology, National Taiwan University, Taipei, Taiwan

${ }^{3}$ Center for Gene Regulation and Signal Transduction Research, National Cheng Kung University, Tainan, Taiwan
Correspondence

should be addressed

to C-Y Chou

Email

chougyn@mail.ncku.edu.tw

\begin{abstract}
Aggressive epithelial ovarian cancers (EOCs) frequently progress and become fatal, even when cytoreduction surgery plus platinum-based chemotherapy are performed. Thus, the early detection of high-risk subgroups is important in order to provide opportunities for better treatment outcomes, using alternative therapeutic strategies. This study aimed to explore the expression of circulating IGF system components and their relationship with treatment outcome in EOC. We included 228 patients with a median follow-up time of 44 months at two tertiary centers. There were 68 cancer deaths and 108 cases of cancer progression in the cohort. Preoperative serum levels of total IGF1, IGF2, IGF-binding protein 2 (IGFBP2), and IGFBP3 were analyzed using an ELISA and were then converted into an IGF1:IGFBP3 molar ratio. The risks of mortality and progression were estimated using Cox regression models in univariate and multivariate analyses. Our results showed that high IGF1, IGF2, and IGFBP3 levels were significantly associated with an early cancer stage, non-serous histology, and optimal cytoreduction. High IGFBP2 levels were associated with an advanced stage and serous histology. Overall and progression-free survival durations were significantly better among patients with high IGF1 $(P=0.003$ and $P=0.001)$, IGF2 $(P=0.003$ and $P=0.02)$, or IGFBP3 levels $(P=0.02$ and $P=0.008)$. In multivariate analysis, serum IGFBP2 levels were significantly associated with increased risk of mortality (hazard ratio $=1.84$, $95 \% \mathrm{Cl}: 1.07-3.18, P=0.03)$, indicating that IGFBP2 could be used as an early predictor of EOCrelated mortality. The combination of elevated IGFBP2 and reduced IGF1 levels at diagnosis could further facilitate the identification of a patient subgroup with the worst prognosis.
\end{abstract}
Key Words
- insulin-like growth factor
- insulin-like growth factor-binding protein
- epithelial ovarian cancer
- response to chemotherapy
- prognosis

Endocrine-Related Cancer (2014) 21, 217-229

\section{Introduction}

Ovarian cancer is the leading cause of gynecological malignancy-related deaths. Annually, an estimated 22280 cases are newly diagnosed and nearly 15500 deaths are attributable to this disease in the USA (Siegel et al. 2012). Epithelial ovarian cancer (EOC) is usually diagnosed at an advanced stage and accounts for the most cases and deaths (Cho \& Shih 2009). Despite cytoreductive surgery followed by combination chemotherapy, many EOC patients eventually relapse with the development of chemoresistant tumors and subsequently die of their disease.

Published by Bioscientifica Ltd. 
To date, there are no good clinical measures for predicting response to chemotherapy. Several groups have used gene expression profiling to generate prognostic signatures (Hartmann et al. 2005, Jazaeri et al. 2005, Tothill et al. 2008). While gene expression analysis can reflect an array of biologically and clinically important characteristics with which to predict cancer prognosis, these analyses require complex computational methods and subsequent acquisition and validation of data to connect an in vitro experimental result with an in vivo result of interest (Chang et al. 2011). Therefore, it is important to develop potential predictive markers to identify disease progression or chemotherapy sensitivity that can be more easily implemented into routine patient care.

The insulin-like growth factor (IGF) system comprises polypeptide ligands (IGF1 and IGF2), receptors, and binding proteins (IGFBPs). The ligands interact with IGF1 receptor (IGF1R), IGF2R, the insulin receptor, or hybrid receptors on cancer cells and thus activate downstream signaling to promote cell growth (Weroha \& Haluska 2012). IGFBPs act as carrier proteins for IGFs to the receptors and modulate IGF transport and tissue distribution to enhance or restrain IGF signaling and bioactivity. IGFBP3 is the major serum carrier of IGFs, whereas IGFBP2 is less common. IGFs have been shown to stimulate invasion, metastasis, and angiogenesis, whereas IGFBPs inhibit IGF bioactivity (Beauchamp et al. 2010). Signaling through IGF1R includes stimulation of cellular proliferation through the RAS-RAF-MAPK pathway and mediation of cell survival through the phosphoinositide-3 kinase-Akt-mammalian target of rapamycin pathway (Scagliotti \& Novello 2012).

Evidence has been accumulated which shows that the IGF system is relevant to the development (Renehan et al. 2004, Gunter et al. 2009, Rinaldi et al. 2010) and poor clinical outcomes (Fuchs et al. 2008, Rohrmann et al. 2012, Rowlands et al. 2012, Duggan et al. 2013) of prostate, breast, pancreatic, and colorectal cancers. According to the literature, a modest association has been shown between higher circulating IGF1 or IGF2 levels and an increased risk of various human cancers (Renehan et al. 2004, Rinaldi et al. 2010, Chi et al. 2013). However, other studies have not shown consistent results (Allen et al. 2007, Pham et al. 2007, Suzuki et al. 2009).

EOCs express high levels of IGF1, IGF2, or IGFBP2 relative to normal ovarian epithelium (Karasik et al. 1994, Sayer et al. 2005, Lancaster et al. 2006), and the increased expression tends to be associated with high-grade and advanced-stage disease (Sayer et al. 2005, Lancaster et al. 2006, Lu et al. 2006). Serum levels of IGFBP2 were shown to be significantly higher and serum IGF1, IGFBP3, and IGFBP5 levels were lower in patients with EOC than in those with benign pathologies and normal controls (Flyvbjerg et al. 1997, Waksmański et al. 2001, Baron-Hay et al. 2004, Lancaster et al. 2006). To our knowledge, few studies have addressed the role of serum IGF2 in EOC. Furthermore, clinical studies have rarely focused on circulating IGF biomarkers and prognosis or response to chemotherapy in EOC, except for a study that showed the association of elevated serum IGFBP2 with early tumor relapse and poor prognosis in 99 patients (Baron-Hay et al. 2004).

CA125, a well-known serum marker, acts as a tumorassociated marker, and its levels are elevated in 50-60\% of patients with early-stage disease. Although CA125 has no diagnostic specificity when screening patients with early-stage disease, it has been widely used in patients with EOC to assess treatment responses to chemotherapy or to detect disease progression (Vergote et al. 2000, Rustin et al. 2004). Preoperative CA125 levels could be of prognostic significance (Jhamb \& Lambrou 2010). However, studies have rarely addressed the correlation between IGF system components and CA125 in ovarian cancer or their individual or adjusted prognostic effects.

To determine whether pretreatment serum levels of IGF1, IGF2, IGFBP2, IGFBP3, and the IGF1:IGFBP3 molar ratio could serve as prognostic markers in patients with EOC, we measured levels of these biomarkers in 228 patients with a diagnosis of EOC at two tertiary care centers. The secondary objective was to examine correlations between the IGF system and clinicopathological variables or their influence on prognosis in EOC patients.

\section{Subjects and methods}

\section{Participant population}

The research protocol and consent form were approved by the Institutional Review Boards of the two hospitals. We included consecutive patients who were diagnosed with EOCs between January 1992 and August 2008 at National Cheng Kung University Hospital (NCKUH) and National Taiwan University Hospital (NTUH), Taiwan. These patients underwent staging or cytoreductive surgery with or without adjuvant chemotherapy. Platinum-based chemotherapeutic agents were used as adjuvant chemotherapy regimens. Radiation therapy was permitted to relieve local discomfort resulting from metastases of the bone, brain, or other sites. Staging was performed according to the clinical staging criteria of the

Published by Bioscientifica Ltd. 
International Federation of Gynecology and Obstetrics (FIGO). Histological classification was defined according to the World Health Organization classification (Lee et al. 2003). Data on levels of preoperative serum CA125 were also available. Patients who had undergone primary surgery elsewhere, whose preoperative blood samples were not available, or who did not provide written informed consent were excluded. Age-matched control participants were selected by random sampling among volunteer sets that comprised cancer-free women. The participants were followed up after treatment, and the date of the latest record retrieved was 31 August 2012. We reviewed the medical records and pathological slides, which provided information on the clinical characteristics, pathological diagnoses, treatments, and outcome. Complete treatment data were available for all included patients.

\section{Clinical definitions}

Preoperative BMI was calculated in units $\left(\mathrm{kg} / \mathrm{m}^{2}\right)$. Optimal cytoreduction was defined as a maximal residual tumor nodule diameter of $<1 \mathrm{~cm}$ or no gross residual disease, whereas suboptimal cytoreduction was defined as a tumor nodule diameter of $\geq 1 \mathrm{~cm}$, according to the Gynecologic Oncology Group guidelines. Response to chemotherapy or progression was defined according to the objective Response Evaluation Criteria in Solid Tumors 1.1 (RECIST 1.1; Eisenhauer et al. 2009) or the Gynecologic Cancer Intergroup definition for CA125 progression (Vergote et al. 2000, Rustin et al. 2004). A complete response (CR) was achieved when all measurable lesions disappeared or when all nonmeasurable lesions disappeared, as reflected by a normalized CA125 level. Partial response (PR) was defined as a $\geq 30 \%$ decrease in the sum of diameters (SOD) of the measurable lesions, compared with the baseline SOD. Progressive disease (PD) was defined as a $\geq 20 \%$ increase in the SOD of the measurable lesions. Stable disease (SD) was defined as insufficient shrinkage to qualify as a PR or an insufficient increase to qualify as PD. PD (progression) also referred to the detection of a new lesion, a sufficient increase in the overall tumor burden in cases of SD, or discontinuation of therapy due to a PR. The term 'responsive' was used to designate either CR or PR, whereas the term 'poorly responsive' was used to designate either SD or PD. Patients who progressed without sustaining clinical benefits after two consecutive chemotherapy courses of platinum-based regimens were classified as refractory. Patients whose diseases recurred in $<6$ months were classified as having platinum-resistant disease, whereas those whose diseases recurred in $>6$ months were defined as having platinum-sensitive disease. The study endpoints were progression-free survival (PFS), overall survival (OS), and the clinical response rate. Both the OS and PFS were calculated from the date of diagnosis. The OS duration was measured to the date of death from any cause; data on survivors were censored on the date at which they were last known to be alive. The PFS duration was measured to the date of first clinical progression or death from any cause, unless the patient was progression free at the time of last contact, in which case PFS duration was measured to the date of last contact.

\section{Collection and storage of blood samples}

Preoperative nonfasting blood samples were drawn from the participants at both institutes. All samples were stored at $\sim 15^{\circ} \mathrm{C}$ and transferred to the central laboratory in each institute, where they were processed and aliquoted in the same manner. All samples were stored in the vapor phases of liquid nitrogen containers $\left(-196^{\circ} \mathrm{C}\right)$ for an average period of $\sim 5$ years before processing. To avoid IGF and IGFBP degradation, none of the aliquoted samples had previously been defrosted.

\section{Preoperative IGF and IGFBP serum levels}

Commercially available ELISA Kits (DSL-10-2800, DSL-102600, DSL-10-6600, and DSL-10-7100) from Diagnostics Systems Laboratories (DSL), Inc. (Webster, TX, USA), with respective sensitivities of $0.01,2.2,0.017$, and $0.04 \mathrm{ng} / \mathrm{ml}$, were used to determine the preoperative concentrations of serum total IGF1, IGF2, IGFBP2, and IGFBP3 respectively. According to the manufacturer's instructions, all blood samples were acidified followed by ethanol precipitation of the IGFBPs fraction before measurement of free IGFs from their binding proteins. The peptide levels were measured in duplicate, and the average of the two measurements was used in data analysis. The measurements were repeated if the correlation coefficient between absorbance and the amount in the standards was $<0.95$. Any test with an intra-assay coefficient of variation $(\mathrm{CV})$ $>10 \%$ was repeated. The respective average intra- and inter-assay CV were 2.8 and $3.6 \%$ for total IGF1, 2.3 and $1.4 \%$ for IGF2, 2.9 and $3.1 \%$ for IGFBP2, and 2.7 and $1.6 \%$ for IGFBP3. The IGF1:IGFBP3 molar ratio was also estimated according to the following conversion: $(0.13 \times$ IGF1 concentration $(\mathrm{ng} / \mathrm{ml})) /(0.036 \times \mathrm{IGFBP} 3$ concentration (ng/ml)) (Rohrmann et al. 2012).

Published by Bioscientifica Ltd. 


\section{Statistical analysis}

Data analyses were performed using the Statistical Package of Social Science, version 17.0 for Windows Software (SPSS, Inc.). Because all IGF system components and CA125 were not normally distributed among the overall patient population or subgroups according to clinicopathological factors, statistical analyses were performed using nonparametric methods. Differences in the concentrations of IGF system components were analyzed using the Mann-Whitney $U$ test between subgroups. Frequency distributions between categorical variables were compared using the $\chi^{2}$ test and Fisher's exact method. Relationships among the IGF system components, CA125, BMI, and age were examined using Kendall's $\tau-b$ test. To study the relationships between the circulating IGF system components and the clinicopathological characteristics at diagnosis, we divided all recruited patients into two subgroups by categorizing each of the clinical or pathological variables. The receiver operating characteristic curve-determined cutoff value was optimized for diagnostic sensitivity and specificity for the prediction of progression or death. The cutoff CA125 value was then chosen with the maximal sensitivity that corresponded to the minimal false positive value for detecting survival. Because insufficient data were available to stratify by tertile, the median values of all IGF components were selected as the cutoff values. Subgroup analyses of IGF biomarker and CA125 expression among 180 patients with different responses to adjuvant chemotherapy were performed according to histology (serous or non-serous type), age ( $<50$ and $\geq 50$ years), and disease progression.

Survival was estimated according to the Kaplan-Meier method and compared using log-rank tests. Cox proportional hazards $(\mathrm{PH})$ models were used to estimate hazard ratios (HR) and CI. The PH assumption for each selected factor was tested, and a log minus log plot of survival resulted in parallel lines, so that $\mathrm{PH}$ held. The following well-known ovarian cancer prognostic factors at the time of diagnosis (Jhamb \& Lambrou 2010) were included in our study: age, stage, histology, residual tumor diameter, and preoperative CA125 level. Each IGF system component was analyzed singly in the univariate analysis and then adjusted for confounders in the multivariate analysis to examine the independent effects on survival and disease progression. A multivariable-adjusted model was adjusted as follows for the factors: age $(<50$ (referent) or $\geq 50$ years), stage (early (referent) or advanced), histology (non-serous (referent) or serous type), residual tumor diameter ( $<1$ (referent) or $\geq 1 \mathrm{~cm}$ ), and hospital
(NCKUH (referent) or NTUH). Given the positive associations between the expression levels of IGF1, IGF2, and IGFBP3, IGF1 was selected and included in the full model. The full model included analyses of IGF1 (stratified as higher (referent) vs lower than the median value), IGFBP2 (stratified as higher vs lower (referent) than the median value), preoperative CA125 level (stratified as higher vs lower (referent) than the cutoff value), age, stage, histology, residual tumor diameter, and hospital. $P$ values $<0.05$ (two-sided) were considered significant.

\section{Results}

\section{Circulating IGF system components and clinicopathological characteristics}

A total of 228 newly diagnosed EOC patients were recruited into our study. The patients ranged in age from 23 to 84 years (mean, 52 years) and in BMI from 15.8 to $43.4\left(\mathrm{~kg} / \mathrm{m}^{2}\right)$ (mean, $22.8 \mathrm{~kg} / \mathrm{m}^{2}$ ). One hundred and twenty-one (53.1\%) patients were postmenopausal women. Eighty-four (36.8\%) patients had FIGO stage I disease, 15 (6.6\%) had stage II disease, 113 (49.6\%) had stage III disease, and 16 (7.0\%) had stage IV disease. Serous histology was found in 101 patients (44.3\%), the endometrioid type in 49 (21.5\%), the clear cell type in $40(17.5 \%)$, and the mucinous type in 38 (16.7\%). Of the 228 patients, 180 (78.9\%) received adjuvant chemotherapy, which consisted of taxane plus platinum or platinum plus cyclophosphamide. Among the 180 patients who underwent first-line chemotherapy, overall response occurred in 133 (73.9\%) patients. Furthermore, $136(75.6 \%)$ had platinum-sensitive disease. The median follow-up time for all participants was 44 months (range, 1-219 months). During follow-up, 109 patients (47.8\%) developed PD and 68 patients (29.8\%) died.

The IGF biomarker expression levels between the agematched control group and the EOC group are listed in Supplementary Table 1 , see section on supplementary data given at the end of this article. The levels of IGF2 and IGFBP3 were significantly higher, whereas IGF1:IGFBP3 molar ratios were significantly lower in the younger EOC patients than the controls ( $\leq 29,30-39$, and $40-49$ years). IGFBP2 levels were higher in EOC patients than in the controls, but the differences did not achieve statistical significance in most of the age subgroups. There were no difference in IGF1 levels between EOC and the agematched control groups. In the control group, a decline in the IGF1 levels and IGF1:IGFBP3 ratio with advancing age was observed, whereas no similar trend was found for the other IGF biomarkers.

Published by Bioscientifica Ltd 
The relationships between the circulating IGF-system in EOC are listed in Table 1. Women who were younger ( $<50$ years), premenopausal, or who had early-stage, nonserous histology, and a residual tumor diameter $<1 \mathrm{~cm}$, had significantly higher serum IGF1, IGF2, and IGFBP3 levels. In addition, the median serum IGF1 and IGFBP3 concentrations were significantly higher in patients without disease progression than in those with disease progression ( $P=0.02$ and $P=0.02$ respectively). The median IGF1 levels were also significantly higher in patients with normalized preoperative CA125 levels. In contrast, the median serum IGFBP2 levels were significantly higher in patients with advanced-stage disease and serous histology. However, the IGF2 or IGFBP2 levels did not differ significantly between patients who did and those who did not show progression. Moreover, the IGF1:IGFBP3 molar ratio did not differ significantly between the categorical subgroups mentioned above (data not shown).

\section{Preoperative serum markers and chemotherapy response}

The relationship between serum markers and chemotherapy response is shown in Table 2. Among the 180 patients who received platinum-based chemotherapy, the levels of all IGF biomarkers did not differ significantly between the platinum-sensitive and platinum-resistant/refractory groups. However, the IGF1 and IGF2 levels were significantly higher in patients who had overall responses (CR/PR) to chemotherapy than in those who had poor responses (SD/PD) $(P=0.04$ and $P=0.04$ respectively). The IGFBP2 levels were significantly higher in those who had poor responses $(P=0.04)$.

Subgroup analyses were performed to examine the expression levels of the circulating biomarkers between patients who were responsive and those who were poorly responsive to platinum-based chemotherapy. Among the serous and older patient subgroups, the IGFBP2 levels were significantly higher in those with poor responses ( $P=0.03$ and $P=0.006$ respectively). No significant difference in the IGFBP2 levels was found between the responsive and poorly responsive patients among the nonserous and young patient subgroups. The IGF2 levels were significantly lower in the poorly responsive patients than in the responsive patients in the subgroup of patients with disease progression $(P=0.02)$. However, the IGF1, IGFBP2, and IGFBP3 levels did not differ in this clinical setting. Furthermore, the preoperative CA125 levels and IGF1:IGFBP3 molar ratios did not differ significantly between patients with overall responses and those with poor responses in the subgroup analyses (data not shown).

\section{CA125}

One hundred and ninety-two (84.2\%) patients had elevated preoperative serum CA125 levels, and this

Table 1 Circulating IGF biomarkers and clinicopathological factors in epithelial ovarian cancer $(n=228)$

\begin{tabular}{|c|c|c|c|c|c|c|c|c|c|c|}
\hline \multirow[b]{2}{*}{ Variable } & \multirow[b]{2}{*}{ Group } & \multirow[b]{2}{*}{$n$} & \multicolumn{2}{|c|}{ IGF1 (ng/ml) } & \multicolumn{2}{|c|}{ IGF2 (ng/ml) } & \multicolumn{2}{|c|}{ IGFBP2 (ng/ml) } & \multicolumn{2}{|c|}{ IGFBP3 (ng/ml) } \\
\hline & & & $\begin{array}{l}\text { Median } \\
\text { (IQR) }\end{array}$ & $P$ & $\begin{array}{l}\text { Median } \\
\text { (IQR) }\end{array}$ & $P$ & $\begin{array}{l}\text { Median } \\
\text { (IQR) }\end{array}$ & $P$ & $\begin{array}{l}\text { Median } \\
\text { (IQR) }\end{array}$ & $P$ \\
\hline \multirow[t]{2}{*}{ Age } & $<50$ & 97 & 138.7 (174.3) & $<0.001$ & $2246.8(1374.4)$ & $<0.001$ & $521.8(1121.2)$ & 0.44 & 3844.5 (3164.2) & 0.02 \\
\hline & $\geq 50$ & 131 & $71.3(101.4)$ & & 1324.9 (1268.6) & & $643.2(2047.7)$ & & $3238.0(3376.2)$ & \\
\hline \multirow[t]{2}{*}{$\mathrm{BMI}$} & $<25$ & 173 & 97.1 (160.9) & 0.53 & $1828.4(1343.4)$ & 0.59 & 645.4 (1595.6) & 0.46 & 3546.7 (3541.6) & 0.41 \\
\hline & $\geq 25$ & 55 & $105.7(142.1)$ & & $1822.8(1511.6)$ & & $414.0(1792.6)$ & & $3777.8(2690.6)$ & \\
\hline \multirow[t]{2}{*}{ Menopause } & No & 107 & $122.9(194.6)$ & 0.002 & $2246.8(1450.0)$ & $<0.001$ & 466.5 (1083.1) & 0.05 & 3844.5 (3365.3) & 0.004 \\
\hline & Yes & 121 & $72.9(101.2)$ & & $1380.3(1239.1)$ & & $761.3(2101.0)$ & & 3169.5 (3120.7) & \\
\hline \multirow[t]{2}{*}{ FIGO stage } & Early & 99 & 158.4 (179.5) & $<0.001$ & $2248.1(1424.8)$ & $<0.001$ & $397.0(774.6)$ & $<0.001$ & 4678.0 (3164.7) & $<0.001$ \\
\hline & Advanced & 129 & 71.3 (82.3) & & $1486.8(1319.0)$ & & $1160.5(2539.2)$ & & $2956.4(2682.3)$ & \\
\hline \multirow[t]{2}{*}{ Cell type } & Serous & 101 & $72.3(90.6)$ & $<0.001$ & $1537.0(1159.8)$ & 0.001 & $947.6(2384.5)$ & 0.001 & $3160.0(2695.9)$ & 0.004 \\
\hline & Non-serous & 127 & $123.9(182.1)$ & & 2124.5 (1495.1) & & $448.8(1047.6)$ & & 4196.3 (3379.4) & \\
\hline \multirow{2}{*}{$\begin{array}{l}\text { Preoperative } \\
\text { CA125 level }\end{array}$} & Normalized & 36 & $153.8(163.5)$ & 0.009 & $2350.3(1541.2)$ & 0.06 & $399.4(644.7)$ & 0.07 & $4345.0(2536.8)$ & 0.06 \\
\hline & Elevated & 192 & $88.2(135.0)$ & & $1672.0(1349.1)$ & & $646.2(1812.2)$ & & $3437.0(3419.8)$ & \\
\hline \multirow{2}{*}{$\begin{array}{l}\text { Residual tumor } \\
\text { diameter }(\mathrm{cm})\end{array}$} & $<1$ & 169 & 117.9 (164.8) & 0.002 & 1947.0 (1435.3) & 0.002 & $586.0(1351.9)$ & 0.59 & 3874.2 (3393.2) & $<0.001$ \\
\hline & $\geq 1$ & 59 & $54.1(78.6)$ & & $1338.3(1422.5)$ & & $564.3(2809.8)$ & & $2707.3(2582.4)$ & \\
\hline \multirow[t]{2}{*}{ Progression } & No & 119 & $121.8(180.2)$ & 0.02 & $2035.4(1670.5)$ & 0.14 & $564.8(1278.1)$ & 0.91 & 3796.3 (3429.1) & 0.02 \\
\hline & Yes & 109 & $81.3(107.8)$ & & $1605.9(1165.2)$ & & $565.4(1816.2)$ & & 3178.9 (3055.6) & \\
\hline
\end{tabular}

Data were analyzed by Mann-Whitney $U$ test. IGF1, insulin-like growth factor 1; IGFBP2, IGF-binding protein 2; IQR, interquartile range.

http://erc.endocrinology-journals.org DOI: 10.1530/ERC-13-0274
(C) 2014 Society for Endocrinology Printed in Great Britain
Published by Bioscientifica Ltd. 
Table 2 Circulating IGF biomarkers, CA125, and response to first-line chemotherapy in epithelial ovarian cancer $(n=180)$

\begin{tabular}{l} 
Subgroup \\
\hline All undergoing chemotherapy \\
Platinum-sensitive \\
Platinum-resistant/-refractory \\
$P$ \\
CR/PR \\
SD/PD \\
$P$ \\
Serous histology \\
CR/PR \\
SD/PD \\
$P$ \\
Non-serous histology \\
CR/PR \\
SD/PD \\
$P$ \\
Older age ( $\geq 50$ years) \\
CR/PR \\
SD/PD \\
$P$ \\
Young age ( $<50$ years) \\
CR/PR \\
SD/PD \\
$P$ \\
Progressor \\
CR/PR \\
SD/PD \\
$P$ \\
\hline
\end{tabular}

$n$
136
44
133
47

67
29

66
18
81
31

52
16
62

\begin{tabular}{c}
$\begin{array}{c}\text { IGF1 }(\mathrm{ng} / \mathrm{ml}) \text {, } \\
\text { median (IQR) }\end{array}$ \\
\hline \\
$91.5(121.5)$ \\
$62.2(94.1)$ \\
0.15 \\
$94.4(120.4)$ \\
$58.2(93.5)$ \\
0.04
\end{tabular}

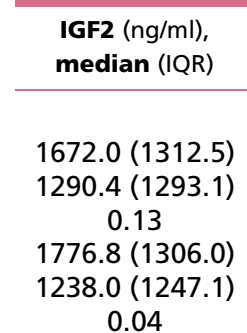

$83.7(90.9)$

$56.9(66.5)$ 0.07

$66 \quad 117.6(147.0)$

$18 \quad 85.5(184.9)$

0.38

$\begin{array}{cc}81 & 71.7(90.2) \\ 31 & 47.1(86.2) \\ & 0.11\end{array}$

$52 \quad 118.8(185.2)$

$16 \quad 82.8(96.3)$

0.12
84.7 (105.1)
$60.2(85.9)$
0.30

$1537.0(1162.2)$

$1223.2(1169.0)$

0.27

$1993.0(1518.4)$

1307.0 (1588.8)

0.12

1320.8 (1135.3)

1056.2 (964.7)

0.28

2226.5 (1307.9)

2106.9 (1271.5)

0.44
1890.5 (1227.8)
1206.0 (1088.6) 0.02

$\begin{gathered}\text { IGFBP2 }(\mathrm{ng} / \mathrm{ml}), \\ \text { median (IQR) }\end{gathered}$
$709.1(1689.6)$
$1237.7(2237.6)$
0.33
$695.3(1471.6)$
$1254.4(3485.2)$
0.04
$817.0(1864.2)$
$1874.8(3660.1)$
0.03
$588.2(1062.2)$
$473.6(1783.7)$
0.64
$695.3(1611.7)$
$1874.8(3707.1)$
0.006
$692.1(1277.7)$
$542.1(1405.1)$
0.65
$489.1(1760.6)$
$716.5(2981.0)$
0.22

CA125 (IU/ml), median (IQR)

331.5 (820.4)

449.8 (761.5)

0.17

$340.0(951.2)$

407.0 (818.6)
0.69

$2725.5(3207.3)$

0.22

$3160.0(2600.5) \quad 599.0(1384.0)$

$2478.2(2881.1) \quad 593.3(1102.5)$ 0.65

0.74

4061.8 (3117.7) $\quad 190.1(343.0)$

0.40

0.24

3238.0 (3401.9)

2485.4 (3356.9)

0.58

348.1 (1187.4)

466.7 (1146.5)

0.53

3769.1 (2675.3)

2979.9 (2777.5)

0.19

321.6 (645.4)

348.7 (553.8)

0.77

3347.4 (2614.5)

2481.8 (3201.5) 0.47
$524.0(1093.4)$

397.8 (661.8) 0.09
$3835.3(3849.1) \quad 90.4(299.2)$

Data were analyzed by Mann-Whitney $U$ test. $C R$, complete response; PR, partial response; SD, stable disease; PD, progressive disease; IQR, interquartile range.

elevation was significantly more frequent in patients with advanced age (patients $\geq 50$ years old, $P=0.02$ ), menopause $(P=0.007)$, advanced stage $(P<0.001)$, serous histology $(P<0.001)$, suboptimal cytoreduction $(P<0.001)$, and disease progression $(P<0.001)$ (data not shown in Table 1). However, preoperative CA125 levels were not significantly different between the responders and poorly responsive patients in the subgroup analyses (Table 2). Of the 228 EOC patients, those with high preoperative CA125 levels exhibited shorter OS and PFS (Supplementary Fig. 1I and J, see section on supplementary data given at the end of this article; $P=0.04$ and $P<0.001$ respectively). In addition, among the 180 patients who received adjuvant chemotherapy, patients with high CA125 levels had poorer OS and PFS $(P=0.03$ and $P=0.001$ respectively) than those with low CA125 levels (Supplementary Fig. 2E and F).

\section{Correlations between serum markers, BMI, and age}

The relationships between circulating CA125, IGF markers, BMI, and age were examined (Table 3). Although Printed in Great Britain moderately positive correlations were found among IGF1, IGF2, and IGFBP3, weak correlations were observed between these three markers and either CA125, BMI, age, or the other IGF biomarkers. Notably, only weak correlations were found with IGFBP2 and the other IGF biomarkers.

\section{IGF system components and clinical outcomes}

The OS and PFS curves for all patients are illustrated in Supplementary Fig. 1. Patients with low IGF1, IGF2, or IGFBP3 levels had significantly poorer OS and PFS than patients with high IGF1 $(P=0.002$ and $P=0.001$ respectively), IGF2 $(P=0.002$ and $P=0.02$ respectively), or IGFBP3 ( $P=0.02$ and $P=0.04$ respectively) levels. In contrast, the OS time was longer in patients with low IGFBP2 levels $(P=0.005)$ than in patients with high levels, although PFS did not differ between the groups.

The survival curves for 180 patients who received adjuvant chemotherapy are illustrated in Supplementary Fig. 2. The patients with low IGF1 levels had shorter OS and PFS than those with high levels (Supplementary

Published by Bioscientifica Ltd 
Table 3 Correlation between IGF biomarkers, CA125, BMI, and age in epithelial ovarian cancer $(n=228)$

\begin{tabular}{|c|c|c|c|c|c|c|c|c|}
\hline & \multirow{2}{*}{$\begin{array}{c}\text { Level, } \\
\text { median (IQR) }\end{array}$} & \multicolumn{7}{|c|}{ Correlation between factors } \\
\hline & & IGF1 $(r)$ & IGF2 (r) & IGFBP3 $(r)$ & IGFBP2 $(r)$ & CA125 $(r)$ & $\mathrm{BMI}(r)$ & Age (r) \\
\hline IGF1 (ng/ml) & $98.1(149.7)$ & - & $0.42 *$ & $0.43 *$ & -0.04 & $-0.12 *$ & 0.00 & $-0.20 *$ \\
\hline IGF2 (ng/ml) & 1822.8 (1473.3) & $0.42 *$ & - & $0.44 *$ & $-0.31 *$ & -0.11 & 0.05 & $-0.31 *$ \\
\hline IGFBP3 (ng/ml) & 3558.5 (3478.6) & $0.43 *$ & $0.44 *$ & - & -0.04 & $-0.17^{\star}$ & 0.08 & $-0.14 *$ \\
\hline IGFBP2 (ng/ml) & $565.1(1615.8)$ & -0.04 & $-0.31 *$ & -0.04 & - & $-0.13^{*}$ & -0.01 & 0.07 \\
\hline CA125 (IU/ml) & $308.6(674.0)$ & -0.12 & -0.11 & $-0.17 *$ & $0.13 *$ & - & -0.03 & $0.12 *$ \\
\hline BMI $\left(\mathrm{kg} / \mathrm{m}^{2}\right)$ & $22.2(4.4)$ & 0.00 & 0.05 & 0.08 & -0.01 & -0.03 & - & -0.03 \\
\hline Age (years) & $51.0(19.0)$ & $-0.20 *$ & $-0.31 *$ & $-0.14^{*}$ & 0.07 & $0.12 *$ & -0.03 & - \\
\hline
\end{tabular}

${ }^{\star} P<0.05$. IGF1, insulin-like growth factor 1; IGFBP2, IGF-binding protein 2; IQR, interquartile range. Data were analyzed by Kendall's $\tau$ - $b$ test.

Fig. 2A and B), but this difference was not statistically significant $(P=0.06$ and $P=0.08$ respectively). OS time, as shown in Supplementary Fig. $2 \mathrm{C}$ and D, was longer in patients with high IGF2 levels and low IGFBP2 levels ( $P=0.004$ and $P=0.002$ respectively), but PFS did not differ between the groups (figure not shown).

\section{Univariate analysis}

The influences of circulating IGF biomarkers at diagnosis or possible prognostic features on the risks of time to death or to disease progression were also estimated using the Cox PH model (Table 4). Low IGF1, IGF2, or IGFBP3 levels and higher IGFBP2 levels were significantly associated with the risk of death. Low IGF1, IGF2, and IGFBP3 but not IGFBP2 levels were significantly associated with an increased risk of disease progression. The IGF1:IGFBP3 molar ratio had no influence on prognosis. Patients with low IGF1 and high IGFBP2 expression levels (subgroup B) had significantly higher risks of death and disease progression than those with high IGF1 and low IGFBP2 expression levels (subgroup A) or those with both low or both high IGF1 and IGFBP2 levels (subgroup C, $n=73$; Fig. $1 \mathrm{~A}$ and $\mathrm{B})$. When compared with 53 subgroup $\mathrm{A}$ patients, 54 subgroup B patients were found to have the most unfavorable outcomes (hazard ratio for death: 4.7, $P<0.001$ and for progression: $2.1, P=0.015)$. The 5-year OS for subgroup B was $52.0 \%$ (87.5\% for early stage EOC and $47.0 \%$ for advanced stage), which was in contrast to the rate of $83.3 \%$ in subgroup A $(90.0 \%$ for early stage EOC and $66.8 \%$ for advanced stage). The 5-year PFS for subgroup B was 39.7\% (66.7\% for early stage EOC and $34.8 \%$ for advanced stage), which was in contrast to the rate of $56.3 \%$ in subgroup A $(72.9 \%$ for early stage EOC and $32.6 \%$ for advanced stage). It is worthy of note that among the 48 patients who did not receive chemotherapy the 5-year OS were 95.5 and 33.3\% for subgroups A and B respectively $(P=0.001)$. Of the 107 premenopausal patients, the 5-year OS were 83.6 and $58.0 \%$ for subgroups $\mathrm{A}$ and $\mathrm{B}$ respectively $(P=0.02)$.

\section{Multivariate analysis}

Table 5 shows the prognostic influence of circulating IGF biomarkers based on age-adjusted and multivariableadjusted Cox PH models. In the age-adjusted model, total IGF1 levels were significantly associated with poor outcomes when the lower and higher levels were compared $(\mathrm{HR}=1.71, P=0.04$ for cancer death and $\mathrm{HR}=1.81$, $P=0.004$ for progression). Higher IGFBP2 levels were significantly associated with an increased risk of cancer death $(\mathrm{HR}=1.80, P=0.02)$, but not of cancer progression. Lower IGFBP3 levels were significantly associated with the risk of progression $(\mathrm{HR}=1.60, P=0.02)$ but not of cancer death. There was no significant association between IGF2 or free IGF1 levels and cancer mortality and progression.

In the multivariable-adjusted model, neither the circulating IGF biomarkers nor the CA125 levels were found to be the predictors of death or disease progression after adjustment. In the full models (Table 6), however, higher IGFBP2 levels $(\mathrm{HR}=1.79, P=0.04)$ and older age $(\mathrm{HR}=1.84, P=0.03)$ were significantly associated with an elevated risk of cancer death. Moreover, advanced-stage disease was an independent predictor of death $(\mathrm{HR}=2.35$, $P=0.02)$ and disease progression $(\mathrm{HR}=2.31, P=0.003)$. There were no associations between total IGF1 or CA125 levels and cancer death after adjusting for the other confounders. In addition, no confounding effect by hospital was found (data not shown). When the platinum-resistant/-refractory status was included as a prognostic factor during primary therapy or post-therapy surveillance in the full model, it was the strongest predictor of death $(\mathrm{HR}=2.81,95 \% \mathrm{CI}: 1.62-4.86 ; P<0.001)$ and progression $(\mathrm{HR}=2.25,95 \% \mathrm{CI}: 1.47-3.46, P<0.001)$. 
Table 4 Univariate analysis of prognostic factors and serum markers in epithelial ovarian cancer $(n=228)$

\begin{tabular}{|c|c|c|c|c|c|c|c|c|}
\hline Variable & $\begin{array}{l}\text { Death } \\
\text { events }\end{array}$ & $\begin{array}{l}\text { Median time } \\
\text { to death } \\
\text { (months) }\end{array}$ & $\begin{array}{l}\text { HR for death } \\
\quad(95 \% \mathrm{Cl})\end{array}$ & $\boldsymbol{P}$ & $\begin{array}{l}\text { Progression } \\
\text { events }\end{array}$ & $\begin{array}{l}\text { Median time to } \\
\text { progression } \\
\text { (months) }\end{array}$ & $\begin{array}{l}\text { HR for } \\
\text { progression } \\
(95 \% \mathrm{Cl})\end{array}$ & $\boldsymbol{P}$ \\
\hline \multicolumn{9}{|l|}{ Serum IGF1 (ng/ml) } \\
\hline Low & 42 & 84 & $2.10(1.28-3.44)$ & 0.003 & 63 & 35 & 1.95 (1.32-2.88) & 0.001 \\
\hline High & 26 & - & 1.00 & & 45 & 61 & 1.00 & \\
\hline \multicolumn{9}{|l|}{ Serum IGF2 (ng/ml) } \\
\hline Low & 43 & 92 & $2.58(1.38-4.79)$ & 0.003 & 56 & 41 & 1.80 (1.09-2.97) & 0.02 \\
\hline High & 25 & - & 1.00 & & 53 & 112 & 1.00 & \\
\hline \multicolumn{9}{|l|}{ Serum IGFBP2 (ng/ml) } \\
\hline High & 44 & 92 & $2.00(1.22-3.30)$ & 0.006 & 53 & 44 & $1.02(0.69-1.49)$ & 0.94 \\
\hline Low & 24 & 168 & 1.00 & & 56 & 54 & 1.00 & \\
\hline \multicolumn{9}{|l|}{ Serum IGFBP3 (ng/ml) } \\
\hline Low & 40 & 92 & $1.78(1.10-2.89)$ & 0.02 & 59 & 43 & $1.68(1.14-2.46)$ & 0.008 \\
\hline High & 28 & - & 1.00 & & 50 & 59 & 1.00 & \\
\hline \multicolumn{9}{|l|}{$\begin{array}{l}\text { Serum IGF1:IGFBP3 } \\
\text { molar ratio }\end{array}$} \\
\hline Low & 37 & 107 & $1.21(0.75-1.95)$ & 0.44 & 57 & 47 & $1.09(0.74-1.61)$ & 0.66 \\
\hline High & 31 & 98 & 1.00 & & 51 & 54 & 1.00 & \\
\hline \multicolumn{9}{|l|}{ Serum CA125 (U/ml) } \\
\hline High & 41 & 77 & $1.68(1.02-2.77)$ & 0.07 & 66 & 29 & $2.14(1.42-3.15)$ & $<0.001$ \\
\hline Low & 25 & 112 & 1.00 & & 39 & 93 & 1.00 & \\
\hline \multicolumn{9}{|l|}{ Age } \\
\hline$\geq 50$ & 48 & 77 & $2.51(1.49-4.23)$ & 0.001 & 65 & 44 & $1.55(1.06-2.29)$ & 0.03 \\
\hline$<50$ & 20 & - & 1.00 & & 44 & 57 & 1.00 & \\
\hline \multicolumn{9}{|l|}{ BMI } \\
\hline$\geq 25$ & 16 & 84 & $1.10(0.63-1.92)$ & 0.75 & 30 & 47 & $1.21(0.79-1.86)$ & 0.39 \\
\hline$<25$ & 52 & 98 & 1.00 & & 79 & 53 & 1.00 & \\
\hline \multicolumn{9}{|l|}{ FIGO stage } \\
\hline Late & 53 & 68 & $3.15(1.77-5.59)$ & $<0.001$ & 82 & 29 & $2.98(1.93-4.62)$ & $<0.001$ \\
\hline Early & 15 & 168 & 1.00 & & 27 & 137 & 1.00 & \\
\hline \multicolumn{9}{|l|}{ Histology } \\
\hline Serous & 40 & 84 & $1.60(0.99-2.61)$ & 0.06 & 67 & 28 & $2.20(1.49-3.24)$ & $<0.001$ \\
\hline Non-serous & 28 & - & 1.00 & & 42 & 158 & 1.00 & \\
\hline \multicolumn{9}{|c|}{$\begin{array}{l}\text { Residual tumor nodule } \\
\text { diameter }(\mathrm{cm})\end{array}$} \\
\hline$\geq 1$ & 27 & 56 & $1.96(1.20-3.20)$ & 0.007 & 40 & 29 & $1.95(1.31-2.89)$ & 0.001 \\
\hline$<1$ & 41 & 112 & 1.00 & & 69 & 58 & 1.00 & \\
\hline \multicolumn{9}{|l|}{ Platinum sensitivity } \\
\hline Resistant/refractory & 30 & 54 & $3.71(2.22-6.18)$ & $<0.001$ & 44 & 17 & $3.02(20.2-4.50)$ & $<0.001$ \\
\hline Sensitive & 30 & 168 & 1.00 & & 56 & 56 & 1 & \\
\hline
\end{tabular}

Data were analyzed by Cox proportional hazard regression model. IGF1, insulin-like growth factor 1; IGFBP2, IGF-binding protein 2.

\section{Discussion}

This study is a comprehensive analysis of EOC patients whose pretreatment IGF serum marker levels correlated with the clinicopathological features, response to chemotherapy, and clinical outcomes. Our conclusions are supported by the following findings: i) high levels of circulating total IGF1, IGF2, and IGFBP3 are associated with favorable clinicopathological characteristics and better outcomes, whereas high IGFBP2 levels are associated with unfavorable prognostic features and prognosis. ii) Low levels of IGF1 or IGF2 and high levels of IGFBP2 correlate with a poor response to chemotherapy. This correlation with IGFBP2 is specifically significant in patients with serous histology and of older age. iii) Serum IGFBP2 levels, age $\geq 50$ years, and advanced-stage disease might serve as independent predictors of EOC-related death after adjusting for clinicopathological variables during the clinical diagnostic phase.

Preclinical findings implicated IGF1 in the induction of cell proliferation and invasion (Cao et al. 2007, Lau \& Leung 2012). Furthermore, the positive effect of IGF1 on ovarian cancer progression was supported by the correlation of increased IGF1 expression in cancer tissues with disease progression (Brokaw et al. 2007) or poor prognosis (Spentzos et al. 2007). Similarly, IGF2 gene expression was found to be increased in tumors with poor prognosis (Sayer et al. 2005, Lu et al. 2006) and to be an independent 

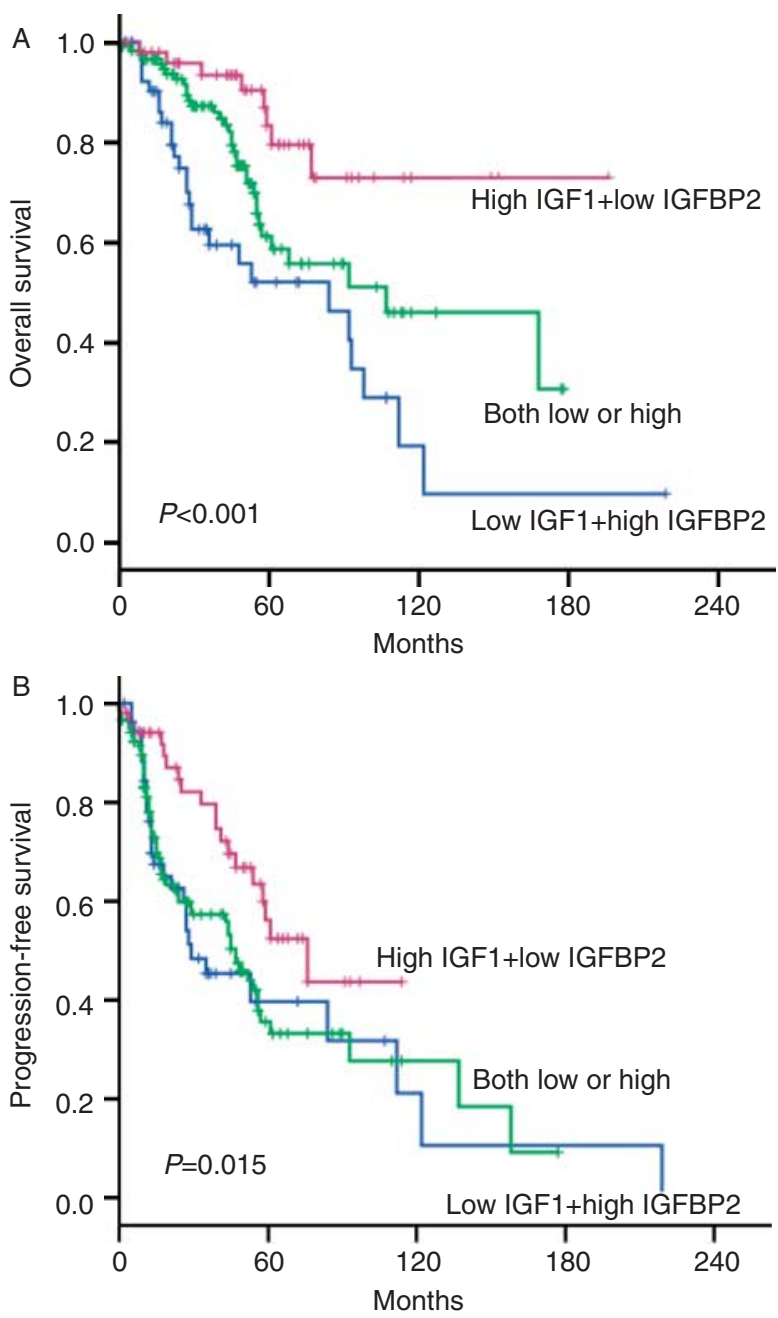

Figure 1

(A) Overall survival (OS) and (B) progression-free survival (PFS) curves of 180 ovarian cancer patients who underwent adjuvant chemotherapy, stratified according to IGF1 expression in combination with IGFBP2. High IGFBP2 levels combined with low IGF1 levels significantly correlated with the poorest 5-year OS and PFS.

predictor of poor survival (Sayer et al. 2005). Regarding chemotherapy resistance, the IGF2 levels were found to be increased in a paclitaxel-resistant cell line, indicating that IGF2 inhibition might facilitate increased paclitaxel sensitivity (Huang et al. 2010).

Recent studies have shown that, in EOC tissues, decreased concentrations of IGFBP3 were significantly associated with advanced stage, suboptimal cytoreduction, and an elevated risk of progression (Katsaros et al. 2001, Lu et al. 2006, Torng et al. 2008). In contrast, one study demonstrated the opposite findings (Walker et al. 2007). Accumulating evidence supports the idea that IGFBP2 might act as a promoter, rather than a tumor suppressor, in EOC. This evidence includes the overexpression of both the IGFBP2 gene and protein in malignant ovarian cyst fluid (Kanety et al. 1996), activated cell invasion in response to IGFBP2 induction (Lee et al. 2005), and the concurrent elevation of IGFBP2 levels in EOC tumor tissues and serum (Lancaster et al. 2006).

The significance of some circulating IGF biomarkers in our cohorts and those of other investigators seems to be distinct from that in the cellular microenvironment as reported in the literature. In contrast to the positive effects of IGF1 and IGF2 on ovarian cancer cell growth and spread, circulating IGF1 and IGF2 are associated with favorable clinicopathological characteristics and better outcomes. Our results differ substantially from other reports that showed no significant correlations between serum IGF1 levels and clinically important prognostic factors (Baron-Hay et al. 2004).

Our results regarding serum IGFBP3 agree to some extent with the previous studies that analyzed tumor samples (Katsaros et al. 2001, Lu et al. 2006, Torng et al. 2008). However, in opposition to our present findings, those studies did not find a significant relationship between IGFBP3 expression and responses to chemotherapy (Katsaros et al. 2001) or OS (Katsaros et al. 2001, Lu et al. 2006) in EOC. Our data agree with the findings (Baron-Hay et al. 2004, Serin et al. 2008) that changes in the serum IGFBP3 levels parallel the changes in IGF1 levels, but differ in that their study did not show correlations between serum IGFBP3 levels and clinicopathological variables (Baron-Hay et al. 2004). In addition, Baron-Hay et al. (2004) showed that the highest tertile of serum IGFBP2 levels in EOC patients was related to advanced stage, serous histology, and an unfavorable outcome. Our results are consistent with their findings and indicate the predictive role of IGFBP2 in prognosis. Future studies might investigate the applications of IGFBP2 for predicting the likelihood of optimal cytoreduction or to monitor chemotherapy response in clinical practice. Furthermore, the development of potential antibodies to target IGFBP2 in the serum or tumor tissues of EOC patients is justified on the basis of these compatible findings in circulation and cancer cells.

Evidence currently exists to support IGF1R targeting in ovarian cancer with an IGF1R kinase inhibitor (e.g. NVP-AEW541, BMS-536924, or BMS-554417), antibodies against IGF1R and hybrid receptors (e.g. 486/STOP or EM164), or AMPK activators (e.g. metformin, C93, or compound C) (Beauchamp et al. 2010). Nevertheless, ligand-targeted strategies (e.g. somatostatin analogues) have had limited success in clinical trials for nonovarian cancers (Pollak 2008a,b, 2012). Our results indicate that

Published by Bioscientifica Ltd. 
Table 5 Variable-adjusted hazard ratio $(95 \% \mathrm{Cls})$ for the association of pretreatment levels of total IGF1, IGF2, IGFBP2, IGFBP3, and IGF1:IGFBP3 molar ratio with the risk of death or disease progression

\begin{tabular}{|c|c|c|c|c|c|c|}
\hline \multirow[b]{2}{*}{ Factor } & \multicolumn{3}{|c|}{ Death } & \multicolumn{3}{|c|}{ Progression } \\
\hline & Low & High & $P$ & Low & High & $P$ \\
\hline IGF1, median cutoff ( $\mathrm{ng} / \mathrm{ml})$ & $<98.1$ & $\geq 98.1$ & & $<98.1$ & $\geq 98.1$ & \\
\hline No. of events/no. of patients & $42 / 114$ & $26 / 114$ & & $63 / 114$ & $45 / 114$ & \\
\hline Age-adjusted HR (95\% CI) & $1.71(1.03-2.85)$ & 1.00 & 0.04 & $1.81(1.21-2.71)$ & 1.00 & 0.004 \\
\hline Multivariable-adjusted HR $(95 \% \mathrm{Cl})$ & $1.37(0.81-2.31)$ & 1.00 & 0.24 & $1.27(0.82-1.94)$ & 1.00 & 0.28 \\
\hline IGF2, median cutoff $(\mathrm{ng} / \mathrm{ml})$ & $<1822.8$ & $\geq 1822.8$ & & $<1822.8$ & $\geq 1822.8$ & \\
\hline No. of events/no. of patients & $43 / 114$ & $\overline{25} / 114$ & & $56 / 114$ & $\overline{53} / 114$ & \\
\hline Age-adjusted HR $(95 \% \mathrm{CI})$ & $1.85(0.96-3.54)$ & 1.00 & 0.06 & $1.39(0.82-2.33)$ & 1.00 & 0.22 \\
\hline Multivariable-adjusted HR $(95 \% \mathrm{Cl})$ & $1.74(0.89-3.41)$ & 1.00 & 0.11 & $1.18(0.69-2.02)$ & 1.00 & 0.54 \\
\hline IGFBP2, median cut-off (ng/ml) & $<565.1$ & $\geq 565.1$ & & $<565.1$ & $\geq 565.1$ & \\
\hline No. of events/no. of patients & 24/114 & $44 / 114$ & & $53 / 114$ & $56 / 114$ & \\
\hline Age-adjusted HR $(95 \% \mathrm{Cl})$ & 1.00 & $1.80(1.09-2.95)$ & 0.02 & 1.00 & $0.96(0.66-1.41)$ & 0.84 \\
\hline Multivariable-adjusted HR $(95 \% \mathrm{Cl})$ & 1.00 & $1.59(0.94-2.70)$ & 0.08 & 1.00 & $0.83(0.56-1.26)$ & 0.39 \\
\hline IGFBP3, median cut-off ( $\mathrm{ng} / \mathrm{ml})$ & $<3558.5$ & $\geq 3558.5$ & & $<3558.5$ & $\geq 3558.5$ & \\
\hline No. of events/no. of patients & $40 / 114$ & $28 / 114$ & & $59 / 114$ & $50 / 114$ & \\
\hline Age-adjusted HR $(95 \% \mathrm{Cl})$ & $1.55(0.95-2.53)$ & 1.00 & 0.08 & $1.60(1.08-2.35)$ & 1.00 & 0.02 \\
\hline Multivariable-adjusted HR $(95 \% \mathrm{Cl})$ & $1.28(0.77-2.14)$ & 1.00 & 0.35 & $1.15(0.76-1.73)$ & 1.00 & 0.50 \\
\hline
\end{tabular}

Data were analyzed by Cox proportional hazard regression model. Multivariable model adjusted for factors at diagnosis: age, stage, histology, residual tumor diameter, and hospital.

the circulating levels of IGF1 or IGF2 differ from those reported for cancer cells in the literature and clarify the protective effects of circulating IGF1 or IGF2 on EOC prognosis. These findings are similar to our previous findings on cervical cancer, which showed an association between reduced total IGF1 levels and an increased risk of cancer death (Huang et al. 2008). This should alert clinicians and might provide an explanation for the failure of ligand-targeted-method implementation in cancer therapy. In addition, our evidence does not support the hypothesis that the unfavorable effects of serum IGF1 or IGF2 are limited to sex-hormone-related cancers (Schaffer et al. 2007). The discrepancies between circulating IGF1 levels and those in the cellular microenvironment might be explained by the following theories: i) racial differences in socioeconomic and dietary influences and ii) paracrine or autocrine influences of
IGFs on cancer cells (Schips et al. 2004, Schillaci et al. 2005, Serin et al. 2008).

The clinical significance of CA125 for cancer screening is limited, and thus, it is recommended as an adjunct in this clinical setting (Sturgeon et al. 2008). Nevertheless, determination of CA125 levels is recommended for treatment monitoring and surveillance for ovarian cancer recurrence. In our cohorts, increased serum CA125 levels at diagnosis were not significantly related to clinically defined platinum sensitivity and chemoresponse in the subgroup analysis. IGFBP2 might serve as a better predictor of chemo-responses in serous histology or older patients.

Our study is limited by a lack of consecutive data with regard to the circulating IGF system components during adjuvant chemotherapy. Further investigation is warranted to determine not only IGF system alterations

Table 6 Full model included multivariate analysis of prognostic factors and serum markers at diagnosis in ovarian cancer $(n=228)$

\section{Variable}

Serum IGF1 level (low vs high)

Serum IGFBP2 level (high vs low)

Serum CA125 level (high vs low)

Age $(\geq 50$ vs $<50)$

FIGO stage (advanced vs early)

Histology (serous vs non-serous)

Residual tumor diameter $(\geq 1 \mathrm{vs}<1 \mathrm{~cm})$

\begin{tabular}{c}
\hline HR $(\mathbf{9 5} \% \mathbf{~ C l )}$ for death \\
\hline $1.49(0.87-2.55)$ \\
$1.79(1.04-3.10)$ \\
$1.10(0.62-1.95)$ \\
$1.84(1.03-3.23)$ \\
$2.35(1.14-4.83)$ \\
$0.74(0.39-1.40)$ \\
$1.53(0.84-2.76)$
\end{tabular}

\begin{tabular}{c}
\hline $\boldsymbol{P}$ \\
\hline 0.15 \\
0.04 \\
0.76 \\
0.03 \\
0.02 \\
0.35 \\
0.16
\end{tabular}

\begin{tabular}{c} 
HR (95\% Cl) for progression \\
\hline $1.33(0.86-2.06)$ \\
$0.85(0.55-1.30)$ \\
$1.28(0.81-2.03)$ \\
$1.26(0.83-1.91)$ \\
$2.31(1.32-4.06)$ \\
$1.31(0.80-2.12)$ \\
$1.01(0.62-1.63)$
\end{tabular}

\begin{tabular}{ll}
\multicolumn{1}{c}{$\boldsymbol{P}$} \\
\hline 0.20 \\
0.44 \\
0.30 \\
0.28 \\
0.003 \\
0.28 \\
0.98
\end{tabular}

Data were analyzed by Cox proportional hazard regression model. Full model adjusted for IGF1, IGFBP2, CA125, age, stage, histology, residual tumor diameter, and hospital.

http://erc.endocrinology-journals.org DOI: $10.1530 /$ ERC-13-0274
(C) 2014 Society for Endocrinology Printed in Great Britain
Published by Bioscientifica Ltd. 
during treatment but also the usefulness of the IGF system in monitoring treatment responses, compared with serial serum CA125 levels. Furthermore, more investigative efforts are needed in order to answer certain unresolved questions by determining the expression of IGF system components in clinical tumor specimens from our cohorts. Another issue is the result of inflation of the type I error rate due to multiple testing in different subgroups. Adjustments for multiple testing are required in a future confirmatory study.

Notwithstanding the limitations, the present largesample study aims to analyze the relationships between preoperative circulating IGF system levels and prognosis for the same EOC patients who were followed for a maximum of 18 years at two tertiary centers. Many essential clinicopathological factors that were included in our analysis and the long-term surveillance periods facilitated the determination of the significance of the influence of target biomarkers on prognosis. We provide evidence that indicates certain roles for circulating IGF biomarkers in EOC clinical outcomes. In our cohorts, the integration of the IGFBP2 and IGF1 levels could help to identify the patients with worse predicted outcomes. The redirection of these patients to alternate therapies such as dose-dense chemotherapy (Katsumata et al. 2009) or the combination of chemotherapy with targeted therapeutic agents (Penson et al. 2010, Heitz et al. 2012) could potentially provide more efficacious therapies to patients with the most aggressive EOCs.

\section{Supplementary data}

This is linked to the online version of the paper at http://dx.doi.org/10.1530/ ERC-13-0274.

\section{Declaration of interest}

The authors declare that there is no conflict of interest that could be perceived as prejudicing the impartiality of the research reported.

\section{Funding}

This work was partly supported by funding 'To establish centers of excellence for cancer research in Taiwan' (DOH101-TD-C-111-003), Department of Health, Executive Yuan, Taiwan.

\section{Acknowledgements}

The authors are grateful to Prof. Yi-Ching Yang and Miss Shang-Chi Lee from the College of Medicine, Biostatistics Consulting Center, National Cheng Kung University Hospital, National Cheng Kung University for providing the statistical consulting services.

\section{References}

Allen NE, Key TJ, Appleby PN, Travis RC, Roddam AW, Rinaldi S, Egevad L, Rohrmann S, Linseisen J, Pischon T et al. 2007 Serum insulin-like growth factor (IGF)-I and IGF-binding protein-3 concentrations and prostate cancer risk: results from the European Prospective Investigation into Cancer and Nutrition. Cancer Epidemiology, Biomarkers \& Prevention 16 1121-1127. (doi:10.1158/1055-9965.EPI-06-1062)

Baron-Hay S, Boyle F, Ferrier A \& Scott C 2004 Elevated serum insulin-like growth factor binding protein-2 as a prognostic marker in patients with ovarian cancer. Clinical Cancer Research 10 1796-1806. (doi:10.1158/ 1078-0432.CCR-0672-2)

Beauchamp MC, Yasmeen A, Knafo A \& Gotlieb WH 2010 Targeting insulin and insulin-like growth factor pathways in epithelial ovarian cancer. Journal of Oncology 2010 257058. (doi:10.1155/2010/257058)

Brokaw J, Katsaros D, Wiley A, Lu L, Su D, Sochirca O, de la Longrais IA, Mayne S, Risch H \& Yu H 2007 IGF-I in epithelial ovarian cancer and its role in disease progression. Growth Factors 25 346-354. (doi:10.1080/ 08977190701838402 )

Cao Z, Liu LZ, Dixon DA, Zheng JZ, Chandran B \& Jiang BH 2007 Insulinlike growth factor-I induces cyclooxygenase- 2 expression via PI3K, MAPK and PKC signaling pathways in human ovarian cancer cells. Cellular Signalling 19 1542-1553. (doi:10.1016/j.cellsig.2007.01.028)

Chang JT, Gatza ML, Lucas JE, Barry WT, Vaughn P \& Nevins JR 2011 SIGNATURE: a workbench for gene expression signature analysis. $B M C$ Bioinformatics 12 443. (doi:10.1186/1471-2105-12-443)

Chi F, Wu R, Zeng YC, Xing R \& Liu Y 2013 Circulation insulin-like growth factor peptides and colorectal cancer risk: an updated systematic review and meta-analysis. Molecular Biology Reports 40 3583-3590. (doi:10.1007/s11033-012-2432-z)

Cho KR \& Shih IeM 2009 Ovarian cancer. Annual Review of Pathology 4 287-313. (doi:10.1146/annurev.pathol.4.110807.092246)

Duggan C, Wang CY, Neuhouser ML, Xiao L, Smith AW, Reding KW, Baumgartner RN, Baumgartner KB, Bernstein L, Ballard-Barbash R et al. 2013 Associations of insulin-like growth factor and insulin-like growth factor binding protein-3 with mortality in women with breast cancer. International Journal of Cancer 132 1191-1200. (doi:10.1002/ijc.27753)

Eisenhauer EA, Therasse P, Bogaerts J, Schwartz LH, Sargent D, Ford R, Dancey J, Arbuck S, Gwyther S, Mooney M et al. 2009 New response evaluation criteria in solid tumours: revised RECIST guideline (version 1.1). European Journal of Cancer 45 228-247. (doi:10.1016/ j.ejca.2008.10.026)

Flyvbjerg A, Mogensen O, Mogensen B \& Nielsen OS 1997 Elevated serum insulin-like growth factor-binding protein 2 (IGFBP-2) and decreased IGFBP-3 in epithelial ovarian cancer: correlation with cancer antigen 125 and tumor-associated trypsin inhibitor. Journal of Clinical Endocrinology and Metabolism 82 2308-2313. (doi:10.1210/jc.82.7.2308)

Fuchs CS, Goldberg RM, Sargent DJ, Meyerhardt JA, Wolpin BM, Green EM, Pitot HC \& Pollak M 2008 Plasma insulin-like growth factors, insulinlike binding protein-3, and outcome in metastatic colorectal cancer: results from intergroup trial N9741. Clinical Cancer Research 14 8263-8269. (doi:10.1158/1078-0432.CCR-08-0480)

Gunter MJ, Hoover DR, Yu H, Wassertheil-Smoller S, Rohan TE, Manson JE, Li J, Ho GY, Xue X, Anderson GL et al. 2009 Insulin, insulin-like growth factor-I, and risk of breast cancer in postmenopausal women. Journal of the National Cancer Institute 101 48-60. (doi:10.1093/jnci/djn415)

Hartmann LC, Lu KH, Linette GP, Cliby WA, Kalli KR, Gershenson D, Bast RC, Stec J, Iartchouk N, Smith DI et al. 2005 Gene expression profiles predict early relapse in ovarian cancer after platinumpaclitaxel chemotherapy. Clinical Cancer Research $112149-2155$. (doi:10.1158/1078-0432.CCR-04-1673)

Heitz F, Harter P, Barinoff J, Beutel B, Kannisto P, Grabowski JP, Heitz J, Kurzeder C \& du Bois A 2012 Bevacizumab in the treatment of ovarian cancer. Advances in Therapy 29 723-735. (doi:10.1007/ s12325-012-0041-9) 
Huang YF, Shen MR, Hsu KF, Cheng YM \& Chou CY 2008 Clinical implications of insulin-like growth factor 1 system in early-stage cervical cancer. British Journal of Cancer 99 1096-1102. (doi:10.1038/ sj.bjc.6604661)

Huang GS, Brouwer-Visser J, Ramirez MJ, Kim CH, Hebert TM, Lin J, Arias-Pulido H, Qualls CR, Prossnitz ER, Goldberg GL et al. 2010 Insulin-like growth factor 2 expression modulates Taxol resistance and is a candidate biomarker for reduced disease-free survival in ovarian cancer. Clinical Cancer Research 16 2999-3010. (doi:10.1158/ 1078-0432.CCR-09-3233)

Jazaeri AA, Awtrey CS, Chandramouli GV, Chuang YE, Khan J, Sotiriou C, Aprelikova O, Yee CJ, Zorn KK, Birrer MJ et al. 2005 Gene expression profiles associated with response to chemotherapy in epithelial ovarian cancers. Clinical Cancer Research 11 6300-6310. (doi:10.1158/ 1078-0432.CCR-04-2682)

Jhamb N \& Lambrou NC 2010 Epidemiology and clinical presentation of ovarian cancer. In Early Diagnosis and Treatment of Cancer: Ovarian Cancer, pp 17-32. Eds RE Bristow \& DK Armstrong. Philadelphia, PA: Sauders Elsevier.

Kanety H, Kattan M, Goldberg I, Kopolovic J, Ravia J, Menczer J \& Karasik A 1996 Increased insulin-like growth factor binding protein-2 (IGFBP-2) gene expression and protein production lead to high IGFBP-2 content in malignant ovarian cyst fluid. British Journal of Cancer 73 1069-1073. (doi:10.1038/bjc.1996.206)

Karasik A, Menczer J, Pariente C \& Kanety H 1994 Insulin-like growth factor-I (IGF-I) and IGF-binding protein-2 are increased in cyst fluids of epithelial ovarian cancer. Journal of Clinical Endocrinology and Metabolism 78 271-276. (doi:10.1210/jc.78.2.271)

Katsaros D, Yu H, Levesque MA, Danese S, Genta F, Richiardi G, Fracchioli S, Khosravi MJ, Diamandi A, Gordini G et al. 2001 IGFBP-3 in epithelial ovarian carcinoma and its association with clinico-pathological features and patient survival. European Journal of Cancer 37 478-485. (doi:10.1016/S0959-8049(00)00423-8)

Katsumata N, Yasuda M, Takahashi F, Isonishi S, Jobo T, Aoki D, Tsuda H, Sugiyama T, Kodama S, Kimura E et al. 2009 Dose-dense paclitaxel once a week in combination with carboplatin every 3 weeks for advanced ovarian cancer: a phase 3, open-label, randomised controlled trial. Lancet 374 1331-1338. (doi:10.1016/S0140-6736(09)61157-0)

Lancaster JM, Sayer RA, Blanchette C, Calingaert B, Konidari I, Gray J, Schildkraut J, Schomberg DW, Marks JR \& Berchuck A 2006 High expression of insulin-like growth factor binding protein-2 messenger RNA in epithelial ovarian cancers produces elevated preoperative serum levels. International Journal of Gynecological Cancer 16 1529-1535. (doi:10.1111/j.1525-1438.2006.00623.x)

Lau MT \& Leung PC 2012 The PI3K/Akt/mTOR signaling pathway mediates insulin-like growth factor 1-induced E-cadherin down-regulation and cell proliferation in ovarian cancer cells. Cancer Letters 326 191-198. (doi:10.1016/j.canlet.2012.08.016)

Lee KR, Russell P, Tavassoli FA, Buckley CH, Prat J, Pisani P, Dietel M, Schwartz P, Gersell DJ, Goldgar DE et al. 2003 Tumours of the ovary and peritoneum. In Pathology and Genetics of Tumor of the Breast and Female Genital Organs, pp 114-202. Eds FA Tavassoli \& P Devilee. Lyon: IARC Press.

Lee EJ, Mircean C, Shmulevich I, Wang H, Liu J, Niemistö A, Kavanagh JJ, Lee JH \& Zhang W 2005 Insulin-like growth factor binding protein 2 promotes ovarian cancer cell invasion. Molecular Cancer 47 . (doi:10.1186/1476-4598-4-7)

Lu L, Katsaros D, Wiley A, Rigault de la Longrais IA, Risch HA, Puopolo M \& Yu H 2006 The relationship of insulin-like growth factor-II, insulin-like growth factor binding protein-3, and estrogen receptor- $\alpha$ expression to disease progression in epithelial ovarian cancer. Clinical Cancer Research 12 1208-1214. (doi:10.1158/1078-0432.CCR-05-1801)

Penson RT, Dizon DS, Cannistra SA, Roche MR, Krasner CN, Berlin ST, Horowitz NS, Disilvestro PA, Matulonis UA, Lee H et al. 2010 Phase II study of carboplatin, paclitaxel, and bevacizumab with maintenance bevacizumab as first-line chemotherapy for advanced Müllerian tumors. Journal of Clinical Oncology 28 154-159. (doi:10.1200/ JCO.2009.22.7900)

Pham TM, Fujino Y, Kikuchi S, Tamakoshi A, Yatsuya H, Matsuda S, Yoshimura T \& JACC Study Group 2007 A nested case-control study of stomach cancer and serum insulin-like growth factor (IGF)-1, IGF-2 and IGF-binding protein (IGFBP)-3. European Journal of Cancer $\mathbf{4 3}$ 1611-1616. (doi:10.1016/j.ejca.2007.04.014)

Pollak M 2008a Targeting insulin and insulin-like growth factor signalling in oncology. Current Opinion in Pharmacology 8 384-392. (doi:10.1016/ j.coph.2008.07.004)

Pollak M 2008 $b$ Insulin and insulin-like growth factor signalling in neoplasia. Nature Reviews. Cancer 8 915-928. (doi:10.1038/nrc2536)

Pollak M 2012 The insulin receptor/insulin-like growth factor receptor family as a therapeutic target in oncology. Clinical Cancer Research $\mathbf{1 8}$ 40-50. (doi:10.1158/1078-0432.CCR-11-0998)

Renehan AG, Zwahlen M, Minder C, O'Dwyer ST, Shalet SM \& Egger M 2004 Insulin-like growth factor (IGF)-I, IGF binding protein-3, and cancer risk: systematic review and meta-regression analysis. Lancet 363 1346-1353. (doi:10.1016/S0140-6736(04)16044-3)

Rinaldi S, Cleveland R, Norat T, Biessy C, Rohrmann S, Linseisen J, Boeing H, Pischon T, Panico S, Agnoli C et al. 2010 Serum levels of IGF-I, IGFBP-3 and colorectal cancer risk: results from the EPIC cohort, plus a meta-analysis of prospective studies. International Journal of Cancer 126 1702-1715. (doi:10.1002/ijc.24927)

Rohrmann S, Grote VA, Becker S, Rinaldi S, Tjønneland A, Roswall N, Grønbæk H, Overvad K, Boutron-Ruault MC, Clavel-Chapelon F et al. 2012 Concentrations of IGF-I and IGFBP-3 and pancreatic cancer risk in the European Prospective Investigation into Cancer and Nutrition. British Journal of Cancer 106 1004-1010. (doi:10.1038/bjc.2012.19)

Rowlands MA, Holly J, Hamdy F, Phillips J, Goodwin L, Marsden G, Gunnell D, Donovan J, Neal D \& Martin R 2012 Serum insulin-like growth factors and mortality in localised and advanced clinically detected prostate cancer. Cancer Causes \& Control 23 347-354. (doi:10.1007/s10552-011-9883-8)

Rustin GJ, Quinn M, Thigpen T, Du Bois A, Pujade-Lauraine E, Jakobsen A, Eisenhauer E, Sagae S, Greven K, Vergote I et al. 2004 Re: new guidelines to evaluate the response to treatment in solid tumors (ovarian cancer). Journal of the National Cancer Institute 96 487-488. (doi:10.1093/jnci/ djh081)

Sayer RA, Lancaster JM, Pittman J, Gray J, Whitaker R, Marks JR \& Berchuck A 2005 High insulin-like growth factor-2 (IGF-2) gene expression is an independent predictor of poor survival for patients with advanced stage serous epithelial ovarian cancer. Gynecologic Oncology 96 355-361. (doi:10.1016/j.ygyno.2004.10.012)

Scagliotti GV \& Novello S 2012 The role of the insulin-like growth factor signaling pathway in non-small cell lung cancer and other solid tumors. Cancer Treatment Reviews 38 292-302. (doi:10.1016/j.ctrv. 2011.07.008)

Schaffer A, Koushik A, Trottier H, Duarte-Franco E, Mansour N, Arseneau J, Provencher D, Gilbert L, Gotlieb W, Ferenczy A et al. 2007 Insulin-like growth factor-I and risk of high-grade cervical intraepithelial neoplasia. Cancer Epidemiology, Biomarkers \& Prevention 16 716-722. (doi:10.1158/ 1055-9965.EPI-06-0924)

Schillaci R, Galeano A, Becu-Villalobos D, Spinelli O, Sapia S \& Bezares RF 2005 Autocrine/paracrine involvement of insulin-like growth factor-I and its receptor in chronic lymphocytic leukaemia. British Journal of Haematology 130 58-66. (doi:10.1111/j.1365-2141.2005.05579.x)

Schips L, Zigeuner R, Ratschek M, Rehak P, Rüschoff J \& Langner C 2004 Analysis of insulin-like growth factors and insulin-like growth factor I receptor expression in renal cell carcinoma. American Journal of Clinical Pathology 122 931-937. (doi:10.1309/G7PYORE7T86HHQYV)

Serin IS, Tanriverdi F, Yilmaz MO, Ozcelik B \& Unluhizarci K 2008 Serum insulin-like growth factor (IGF)-I, IGF binding protein (IGFBP)-3, leptin concentrations and insulin resistance in benign and malignant epithelial ovarian tumors in postmenopausal women. Gynecological Endocrinology 24 117-121. (doi:10.1080/09513590801895559) http://erc.endocrinology-journals.org

DOI: 10.1530/ERC-13-0274
(C) 2014 Society for Endocrinology Printed in Great Britain 
Siegel R, Naishadham D \& Jemal A 2012 Cancer statistics, 2012. CA: A Cancer Journal for Clinicians 62 10-29. (doi:10.3322/caac.20138)

Spentzos D, Cannistra SA, Grall F, Levine DA, Pillay K, Libermann TA \& Mantzoros CS 2007 IGF axis gene expression patterns are prognostic of survival in epithelial ovarian cancer. Endocrine-Related Cancer 14 781-790. (doi:10.1677/ERC-06-0073)

Sturgeon CM, Duffy MJ, Stenman UH, Lilja H, Brünner N, Chan DW, Babaian R, Bast RC Jr, Dowell B, Esteva FJ et al. 2008 National Academy of Clinical Biochemistry. National Academy of Clinical Biochemistry laboratory medicine practice guidelines for use of tumor markers in testicular, prostate, colorectal, breast, and ovarian cancers. Clinical Chemistry 54 e11-e79. (doi:10.1373/clinchem.2008.105601)

Suzuki S, Kojima M, Tokudome S, Suzuki K, Ozasa K, Ito Y, Inaba Y, Tajima K, Nakachi K, Watanabe Y et al. 2009 Insulin-like growth factor (IGF)-I, IGF-II, IGF binding protein-3, and risk of colorectal cancer: a nested case-control study in the Japan Collaborative Cohort Study. Asian Pacific Journal of Cancer Prevention 10 (Suppl) 45-49.

Torng PL, Lee YC, Huang CY, Ye JH, Lin YS, Chu YW, Huang SC, Cohen P, Wu CW \& Lin CT 2008 Insulin-like growth factor binding protein-3 (IGFBP-3) acts as an invasion-metastasis suppressor in ovarian endometrioid carcinoma. Oncogene 27 2137-2147. (doi:10.1038/ sj.onc.1210864)
Tothill RW, Tinker AV, George J, Brown R, Fox SB, Lade S, Johnson DS, Trivett MK, Etemadmoghadam D, Locandro B et al. 2008 Novel molecular subtypes of serous and endometrioid ovarian cancer linked to clinical outcome. Clinical Cancer Research 14 5198-5208. (doi:10.1158/1078-0432.CCR-08-0196)

Vergote I, Rustin GJ, Eisenhauer EA, Kristensen GB, Pujade-Lauraine E, Parmar MK, Friedlander M, Jakobsen A \& Vermorken JB 2000 Re: new guidelines to evaluate the response to treatment in solid tumors [ovarian cancer]. Gynecologic Cancer Intergroup. Journal of the National Cancer Institute 92 1534-1535. (doi:10.1093/jnci/92.18.1534)

Waksmański B, Dudkiewicz J \& Kowalski T 2001 Changes in insulin-like growth factor I, 17- $\beta$-estradiol, and progesterone in postmenopausal women with benign and malignant ovarian tumours. Medical Science Monitor 7 919-923.

Walker G, MacLeod K, Williams AR, Cameron DA, Smyth JF \& Langdon SP 2007 Insulin-like growth factor binding proteins IGFBP3, IGFBP4, and IGFBP5 predict endocrine responsiveness in patients with ovarian cancer. Clinical Cancer Research 13 1438-1444. (doi:10.1158/ 1078-0432.CCR-06-2245)

Weroha SJ \& Haluska P 2012 The insulin-like growth factor system in cancer. Endocrinology and Metabolism Clinics of North America $\mathbf{4 1}$ 335-350. (doi:10.1016/j.ecl.2012.04.014)

Received in final form 12 November 2013

Accepted 21 November 2013

Made available online as an Accepted Preprint

22 November 2013
(C) 2014 Society for Endocrinology Printed in Great Britain
Published by Bioscientifica Ltd 